\title{
The Potential Use of Metabolic Cofactors in Treatment of NAFLD
}

\author{
Adil Mardinoglu ${ }^{1,2, *}$, Dilek Ural ${ }^{3}{ }^{\circledR}$, Mujdat Zeybel ${ }^{4}$, Hatice Hilal Yuksel ${ }^{1}$, Mathias Uhlén ${ }^{1}$ \\ and Jan Borén ${ }^{5}$ \\ 1 Science for Life Laboratory, KTH-Royal Institute of Technology, SE-17121 Stockholm, Sweden \\ 2 Centre for Host-Microbiome Interactions, Faculty of Dentistry, Oral \& Craniofacial Sciences, King's College \\ London, London SE1 9RT, UK \\ 3 School of Medicine, Koç University, Istanbul 34450, Turkey \\ 4 Department of Gastroenterology and Hepatology, School of Medicine, Koç University, Istanbul 34450, Turkey \\ 5 Department of Molecular and Clinical Medicine, University of Gothenburg and Sahlgrenska University \\ Hospital Gothenburg, 41345 Gothenburg, Sweden \\ * Correspondence: adilm@scilifelab.se
}

Received: 1 May 2019; Accepted: 5 July 2019; Published: 12 July 2019

\begin{abstract}
Non-alcoholic fatty liver disease (NAFLD) is caused by the imbalance between lipid deposition and lipid removal from the liver, and its global prevalence continues to increase dramatically. NAFLD encompasses a spectrum of pathological conditions including simple steatosis and non-alcoholic steatohepatitis (NASH), which can progress to cirrhosis and liver cancer. Even though there is a multi-disciplinary effort for development of a treatment strategy for NAFLD, there is not an approved effective medication available. Single or combined metabolic cofactors can be supplemented to boost the metabolic processes altered in NAFLD. Here, we review the dosage and usage of metabolic cofactors including L-carnitine, Nicotinamide riboside (NR), L-serine, and $\mathrm{N}$-acetyl-L-cysteine (NAC) in human clinical studies to improve the altered biological functions associated with different human diseases. We also discuss the potential use of these substances in treatment of NAFLD and other metabolic diseases including neurodegenerative and cardiovascular diseases of which pathogenesis is linked to mitochondrial dysfunction.
\end{abstract}

Keywords: NAFLD; metabolic cofactors; L-carnitine; nicotinamide riboside; L-serine; $\mathrm{N}$-acetyl-L-cysteine

\section{Introduction}

Non-alcoholic fatty liver disease (NAFLD) is a consequence of the imbalance between deposition and removal of lipids from the liver [1-3]. The global prevalence of NAFLD continues to increase dramatically and has reached $25 \%$ at the population level [4-7]. NAFLD includes a spectrum of pathological conditions, ranging from simple steatosis to hepatic inflammation referred as non-alcoholic steatohepatitis (NASH), which can progress to cirrhosis and hepatocellular carcinoma (HCC) [8-10]. Even though hepatic steatosis and fibrosis are reversible conditions, decompensated cirrhosis is frequently associated with irreversible hepatic damage, and transplantation is considered to be the only possible treatment option.

Oxidative stress and inflammatory responses have major role in the pathogenesis of NAFLD and its progression to NASH. NAFLD is also closely linked to complex metabolic conditions including obesity, type 2 diabetes mellitus (T2DM) and cardiovascular diseases (CVD) [11]. Considering the complexity associated with the drug development that can be used in effective treatment of the patients, supplementation of natural substances that can activate the altered metabolic pathways in NAFLD can 
be used in treatment of the patients. Supplementation of such metabolic cofactors may also improve the metabolic parameters in NAFLD patients and stop progression of the disease to severe form of the diseases including NASH, cirrhosis and HCC. To date, a number of metabolic cofactors have been supplemented to patients with different metabolic disorders and its positive effect has been shown in placebo controlled human clinical studies (Table 1 and Table S1).

The pathogenesis of NASH is a rather complex process consisting of lipid accumulation, hepatocellular injury, recruitment and activation of inflammatory and hepatic stellate cells, and fibrogenesis $[8,10]$. At earlier stages, lipid accumulation is a critical phase arising from increased dietary fatty acids and de novo lipogenesis and insufficient capacity for lipid removal by fatty acid oxidation and lipoprotein secretion. Elucidation of pathophysiological responses and cellular dysfunction induced by lipid accumulation is essential to develop efficient treatment strategies for NAFLD and other complex metabolic diseases including T2DM and CVD [12]. Such diseases have been frequently studied based on a single gene or a specific pathway. With the "omics" revolution that enable the generation of enormous amounts of data (i.e., genomics, transcriptomics, proteomics, lipidomics, metabolomics, fluxomics, epigenetics, and metagenomics), identification of key genes and essential pathways driving steatosis, steatohepatitis and fibrosis in NAFLD is possible using a holistic systems biology approach $[13,14]$. However, analyzing multi-layer omics data to understand the pathophysiology is a challenging task.

Systems biology enables the integration and analysis of multi-layer omics data to make predictions that can be experimentally tested [15-20]. This integrative approach has successfully been used in various contexts in medical research over the last decade. We have recently performed systems level analysis by combining clinical studies with stable isotopes, in-depth multi-omics profiling and personalized network analysis, and revealed the underlying mechanisms of NAFLD to developing novel strategies for its prevention and treatment $[16,20,21]$. Our integrated analysis indicated that there is an augmented requirement for Nicotinamide adenine dinucleotide (NAD)+ and reduced glutathione (GSH) in patients with NAFLD. This observation was further validated using liver transcriptomics and plasma metabolomics data. We also performed a mouse supplementation study with the precursors for NAD+ (Nicotinamide riboside [NR]) and GSH (L-serine [serine] and N-acetyl-L-cysteine [NAC]), and a proof of concept human supplementation study with serine to decrease the hepatic steatosis.

Our analysis indicated that a three-step strategy including (i) increasing mitochondrial fatty acid uptake, (ii) increasing mitochondrial fatty acid oxidation, and (iii) increasing the availability of GSH can be applied to decrease the amount of hepatic steatosis in NAFLD patients. Single or combined metabolic cofactors can be supplemented to boost these metabolic processes altered in NAFLD. Supplementation of (i) L-carnitine (carnitine) may stimulate the transfer of fatty acids from cytosol to mitochondria, (ii) NR may provide required amount of NAD+ which is essential for mitochondrial fatty acid oxidation, and (iii) serine and NAC may increase the level of GSH in the cells (Figure 1). Here, we conducted a literature review about the use of individual metabolic cofactors including carnitine, NR, serine and NAC, in human clinical studies to treat different disorders. We also provided a guideline for use of these metabolic cofactors by reviewing different human clinical studies and observed that careful screening of the patients during human clinical studies may decrease the risk associated with the combination of metabolic cofactors. 
Table 1. The dosages of the Nicotinamide Riboside, L-serine, and L-carnitine used in previous human trials. The data retrieved from https://clinicaltrials.gov. The dosage of the $\mathrm{N}$-acetyl-L-cysteine is provided in Table S1.

\begin{tabular}{|c|c|c|c|c|}
\hline NCT Number & Title & Dosage & Conditions & Phases \\
\hline & Nicotinamide Riboside (All Studies) & & & \\
\hline NCT03423342 & Nicotinamide Riboside in Systolic Heart Failure & $500-2000 \mathrm{mg} / \mathrm{day}$ & Heart Failure, Systolic & Phase 1|Phase 2 \\
\hline NCT02689882 & Pharmacokinetic Study of Nicotinamide Riboside & 500-2000 mg/day & Metabolic Disturbance & Phase 1 \\
\hline NCT03432871 & Nicotinamide Riboside and Mitochondrial Biogenesis & $10 \mathrm{mg} / \mathrm{kg} /$ day & Mitochondrial Diseases & Not Applicable \\
\hline NCT02835664 & Nicotinamide Riboside and Metabolic Health & $1000 \mathrm{mg} /$ day & $\begin{array}{l}\text { Obesity|Insulin Resistance } \\
\text { Atherosclerosis|Diabetes|Coronary }\end{array}$ & Not Applicable \\
\hline NCT02812238 & Study to Evaluate the Effect of Nicotinamide Riboside on Immunity & $1000 \mathrm{mg} /$ day & Artery Disease & Phase 2 \\
\hline NCT03685253 & $\begin{array}{l}\text { Nicotinamide Riboside for Diabetic Neuropathy } \\
\text { Safety \& Efficacy of Nicotinamide Riboside Supplementation for }\end{array}$ & $1000 \mathrm{mg} /$ day & Diabetic Neuropathy Peripheral & Phase 1|Phase 2 \\
\hline NCT02921659 & $\begin{array}{l}\text { Improving Physiological Function in Middle-Aged and Older Adults } \\
\text { Nicotinamide Riboside With and Without Resveratrol to Improve }\end{array}$ & $1000 \mathrm{mg} /$ day & Aging & Phase 1|Phase 2 \\
\hline NCT03743636 & $\begin{array}{l}\text { Functioning in Peripheral Artery Disease } \\
\text { Effects of Vitamin B3 Derivative Nicotinamide Riboside (NR) in Bone, }\end{array}$ & $1000 \mathrm{mg} /$ day & Peripheral Artery Disease & Phase 3 \\
\hline NCT03818802 & $\begin{array}{l}\text { Skeletal Muscle and Metabolic Functions in Aging } \\
\text { Trial of Nicotinamide Riboside and Co-enzyme Q10 in Chronic Kidney }\end{array}$ & $1000 \mathrm{mg} /$ day & $\begin{array}{l}\text { Healthy Elderly Volunteers } \\
\text { Chronic Kidney }\end{array}$ & Not Applicable \\
\hline NCT03579693 & Disease & $1200 \mathrm{mg} /$ day & Disease|Sarcopenia|Frailty & Phase 2 \\
\hline NCT03727646 & $\begin{array}{l}\text { Nicotinamide Riboside in LVAD Recipients } \\
\text { Nicotinamide Riboside on Mitochondrial Function in Li-Fraumeni }\end{array}$ & $2000 \mathrm{mg} /$ day & $\begin{array}{l}\text { Heart Failure } \\
\text { Cancer|Skin Fibroblasts|Muscle }\end{array}$ & Early Phase 1 \\
\hline NCT03789175 & Syndrome & $500-2000 \mathrm{mg} /$ day & Weakness & Phase 1|Phase 2 \\
\hline NCT03501433 & $\begin{array}{l}\text { Effects of Nicotinamide Riboside on Metabolism and Vascular Function } \\
\text { Nicotinamide Riboside for Treating Elevated Systolic Blood Pressure and }\end{array}$ & $500 \mathrm{mg} /$ day & Aging|Lipemia & Not Applicable \\
\hline NCT03821623 & $\begin{array}{l}\text { Arterial Stiffness in Middle-aged and Older Adults } \\
\text { Evaluation of Nicotinamide Riboside in Prevention of Small Fiber Axon }\end{array}$ & 1000 mg/day & Hypertension|Aging & Phase 2 \\
\hline NCT03912220 & $\begin{array}{l}\text { Degeneration and Promotion of Nerve Regeneration } \\
\text { Effect of Nicotinamide Riboside and Pterostilbene Supplementation on }\end{array}$ & $1800 \mathrm{mg} /$ day & Small Fiber Neuropathy & Phase 2 \\
\hline NCT03754842 & $\begin{array}{l}\text { Muscle Regeneration in Elderly Humans } \\
\text { The Effects of Nicotinamide Riboside Supplementation on NAD+/NADH }\end{array}$ & $1000 \mathrm{mg} /$ day & Muscle Injury & Not Applicable \\
\hline NCT03151707 & $\begin{array}{l}\text { Ratio and Bioenergetics } \\
\text { The Effect of Nicotinamide Riboside on Skeletal Muscle Function in Heart }\end{array}$ & $1000 \mathrm{mg} /$ day & Healthy & Phase 4 \\
\hline NCT03565328 & Failure Subjects & $500-2000 \mathrm{mg} /$ day & $\begin{array}{l}\text { Heart Failure } \\
\text { Chemotherapy-induced Peripheral }\end{array}$ & Phase 2 \\
\hline NCT03642990 & NR in Chemo-induced Peripheral Neuropathy & $300-1000 \mathrm{mg} /$ day & Neuropathy & Phase 2 \\
\hline NCT03951285 & $\begin{array}{l}\text { Nicotinamide Riboside and Mitochondrial Metabolism } \\
\text { A Study by ChromaDex to Assess the Effects of TRU NIAGEN on }\end{array}$ & $250-1000 \mathrm{mg} /$ day & Obesity & Not Applicable \\
\hline NCT03562468 & Cognitive Function, Mood and Sleep in Older Adults & $300-1000 \mathrm{mg} /$ day & Cognitive Function|Mood|Sleep & Not Applicable \\
\hline
\end{tabular}


Table 1. Cont

\begin{tabular}{|c|c|c|c|c|}
\hline NCT Number & Title & Dosage & Conditions & Phases \\
\hline & \multicolumn{4}{|l|}{ Nicotinamide Riboside (All Studies) } \\
\hline & & & Ataxia Telangiectasia|ATM Gene & \\
\hline NCT03962114 & Effects of Vitamin B3 in Patients With Ataxia Telangiectasia & $25 \mathrm{mg} / \mathrm{kg} /$ day & Mutation & Phase 2 \\
\hline NCT02300740 & Pharmacokinetic Analysis of Nicotinamide Riboside & 500-1000 mg/day & Healthy Participants & Early Phase 1 \\
\hline NCT02712593 & $\begin{array}{l}\text { A Study Investigating the Effects of Niagen in Healthy Adults. } \\
\text { Use of 31P MRS to Assess Brain NAD+ in Healthy Current and Former }\end{array}$ & $100-1000 \mathrm{mg} /$ day & Bioavailability & Phase 2 \\
\hline NCT02721537 & $\begin{array}{l}\text { Collegiate Athletes } \\
\text { Pharmacokinetics, Pharmacodynamics and Safety of Basis in Acute Kidney }\end{array}$ & $750 \mathrm{mg} /$ day & Concussion, Mild & Not Applicable \\
\hline NCT03176628 & $\begin{array}{l}\text { Injury Study } \\
\text { The Effect of Vitamin B3 on Substrate Metabolism, Insulin Sensitivity, and }\end{array}$ & 500-2000 mg/day & Acute Kidney Injury & Not Applicable \\
\hline NCT02303483 & $\begin{array}{l}\text { Body Composition in Obese Men } \\
\text { A Study of the Pharmacokinetics of Three Dosages of Niagen in Healthy }\end{array}$ & 2000 mg/day & Obese & Not Applicable \\
\hline NCT02191462 & $\begin{array}{l}\text { Subjects } \\
\text { Nicotinamide Adenine Dinucleotide and Skeletal Muscle Metabolic }\end{array}$ & 100-1000 mg/day & Pharmacokinetics & Phase 1 \\
\hline NCT02950441 & $\begin{array}{l}\text { Phenotype } \\
\text { A Randomized Controlled Trial of Nicotinamide Supplementation in Early }\end{array}$ & 1000 mg/day & Aging & Phase 2 \\
\hline NCT03568968 & $\begin{array}{l}\text { Parkinson's Disease } \\
\text { The Effects of Nicotinamide Adenine Dinucleotide (NAD) on Brain }\end{array}$ & 1000 mg/day & Parkinson Disease & Not Applicable \\
\hline NCT02942888 & $\begin{array}{l}\text { Function and Cognition } \\
\text { A Study to Evaluate Safety and Health Benefits of Basis Among Elderly }\end{array}$ & 250-1000 mg/day & Mild Cognitive Impairment|NAD & Not Applicable \\
\hline \multirow[t]{2}{*}{ NCT02678611 } & Subjects. & $250-500 \mathrm{mg} /$ day & Safety: Healthy Subjects & Phase 1 \\
\hline & L-serine (All Studies) & & & \\
\hline NCT02528994 & Short Term Dietary Serine Supplementation and Circulating Serine Levels & 6-48 g/day & Bioavailability & Not Applicable \\
\hline NCT03062449 & Phase IIa L-serine Trial for eAD & $30 \mathrm{~g} / \mathrm{day}$ & $\begin{array}{l}\text { Alzheimer Disease } \\
\text { Amyotrophic Lateral Sclerosis }\end{array}$ & Phase 2 \\
\hline NCT01835782 & $\begin{array}{l}\text { Determining the Safety of L-serine in ALS } \\
\text { Tolerability and Efficacy of L-Serine in Patients With Amyotrophic Lateral }\end{array}$ & $1-30$ g/day & (ALS) & Phase $1 \mid$ Phase 2 \\
\hline NCT03580616 & Sclerosis (ALS) & $30 \mathrm{~g} /$ day & $\begin{array}{l}\text { Amyotrophic Lateral Sclerosis } \\
\text { Hereditary Sensory and Autonomic }\end{array}$ & Phase 2 \\
\hline NCT01733407 & L-Serine Supplementation in Hereditary Sensory Neuropathy Type 1 & $0.4 \mathrm{~g} / \mathrm{kg} /$ day & Neuropathy Type I & Phase $1 \mid$ Phase 2 \\
\hline NCT02599038 & Serine Supplementation for Obese Subjects With Fatty Liver Disease & $0.2 \mathrm{~g} / \mathrm{kg} /$ day & Non-alcoholic Fatty Liver Disease & Phase $1 \mid$ Phase 2 \\
\hline
\end{tabular}


Table 1. Cont

\begin{tabular}{|c|c|c|c|c|}
\hline NCT Number & Title & Dosage & Conditions & Phases \\
\hline & L-carnitine (Completed Studies) & & & \\
\hline \multirow[t]{2}{*}{ NCT03953248 } & L-Carnitine as an Adjuvant Treatment in Acute Phosphide Poisoning (LC) & $1000 \mathrm{mg} / 8 \mathrm{~h}$ & Toxicity & Early Phase 1 \\
\hline & Effects of a Bakery Product Enriched With Fibre and L-carnitine on Insulin & & Metabolic X & \\
\hline NCT02281253 & Resistance in Patients With Metabolic Syndrome & $2325 \mathrm{mg} /$ day & Syndrome|Overweight|Dyslipidemias & Not Applicable \\
\hline \multirow[t]{2}{*}{ NCT03008356 } & $\mathrm{L}$-carnitine for Fatigue in COPD & $2000 \mathrm{mg} /$ day & Copd|Fatigue & Phase 2|Phase 3 \\
\hline & Combination Therapy of Hydroxyurea With L-Carnitine and Magnesium & & & \\
\hline \multirow[t]{2}{*}{ NCT00809042 } & Chloride in Thalassemia Intermedia & $250 \mathrm{mg} /$ day & $\mathbb{E} \leq-$ Thalassemia Intermedia & Phase 2 \\
\hline & Effects of L-Carnitine on Postprandial Clearance of Triglyceride-rich & & & \\
\hline NCT00386971 & $\begin{array}{l}\text { Lipoproteins in HIV Patients on HAART } \\
\text { L-Carnitine and Clomiphene Citrate for Induction of Ovulation in Women }\end{array}$ & $3000 \mathrm{mg} /$ day & Hyperlipidemia|HIV Infections & Not Applicable \\
\hline NCT03476356 & $\begin{array}{l}\text { With Polycystic Ovary Syndrome } \\
\text { The Clinical Study of the Efficacy and Safety of L-Carnitine Injection in }\end{array}$ & $3000 \mathrm{mg} /$ day & Polycystic Ovary Syndrome & Not Applicable \\
\hline NCT01580553 & $\begin{array}{l}\text { Treatment of Heart Failure } \\
\text { Adding L-Carnitine to Clomiphene Citrate for Induction of Ovulation in }\end{array}$ & $1000 \mathrm{mg} /$ day & Heart Failure, & Phase 2|Phase 3 \\
\hline NCT03630341 & $\begin{array}{l}\text { Women With Polycystic Ovary Syndrome } \\
\text { Ability of L-carnitine to Prevent Heart Damage in Breast Cancer Patients }\end{array}$ & 1000 mg/day & Polycystic Ovary Syndrome & Phase 4 \\
\hline NCT00247975 & Receiving Anthracycline Chemotherapy & $3000 \mathrm{mg} /$ day & Heart Failure & Phase 2|Phase 3 \\
\hline NCT00822172 & Evaluation of Cilostazol in Combination With L-Carnitine & $2000 \mathrm{mg} /$ day & Peripheral Vascular Disease & Phase 4 \\
\hline NCT01769157 & Effects of L-carnitine on Hypothyroidism & $1980 \mathrm{mg} /$ day & Hypothyroidism & Phase 4 \\
\hline NCT01232907 & The Effects of L-carnitine on Fatigue in Spinal Cord Injury & 1980 mg/day & Spinal Cord Injury (SCI) & Phase 2 \\
\hline NCT00841295 & Effects of Parenteral L-carnitine Supplementation in Premature Neonates & $10 \mathrm{mg} / \mathrm{kg} /$ day & Complication of Prematurity & Not Applicable \\
\hline NCT02692235 & $\begin{array}{l}\text { Carnitine Supplementation and Skeletal Muscle Function } \\
\text { Efficacy of L-carnitine Versus Placebo in the Treatment of Fatigue in }\end{array}$ & $1500 \mathrm{mg} /$ day & Sarcopenia & Phase 3 \\
\hline NCT01149525 & Multiple Sclerosis & $4000 \mathrm{mg} /$ day & Multiple Sclerosis & Phase 3 \\
\hline NCT02322697 & Effect of Carnitine on Uremic Cardiomyopathy & $1000 \mathrm{mg} /$ dialysis & $\begin{array}{l}\text { Disorder of Fatty Acid Metabolism } \\
\text { Diabetes Mellitus, Type }\end{array}$ & Not Applicable \\
\hline NCT00351234 & $\begin{array}{l}\text { Carnitine Levels and Carnitine Supplementation in Type I Diabetes } \\
\text { Effect of Carnitine tartrate Supplementation and Resistance Training on }\end{array}$ & $100 \mathrm{mg} / \mathrm{kg}$ & I|Hypoglycemia & Not Applicable \\
\hline NCT03907592 & $\begin{array}{l}\text { Skeletal Muscle Function } \\
\text { Effect of Oral L-carnitine Supplement on Lipid Profile, Anemia, and }\end{array}$ & $1000 \mathrm{mg} /$ day & Sarcopenia & Not Applicable \\
\hline NCT01278693 & Quality of Life of Patients & $1000 \mathrm{mg} /$ day & Complication of Hemodialysis & Phase 2 \\
\hline NCT01665092 & Rapid Administration of Carnitine in sEpsis & $6000-18000 \mathrm{mg} /$ day & Septic Shock & Phase 2 \\
\hline NCT00227266 & Valproic Acid and Carnitine in Patients With Spinal Muscular Atrophy & $1000-10000 \mathrm{mg} /$ day & Spinal Muscular Atrophy & Phase 2 \\
\hline NCT00079599 & $\begin{array}{l}\text { L-Carnitine to Treat Fatigue in AIDS Patients } \\
\text { L-carnitine and Coenzyme Q10 in Relation to the Oxidative Stress, }\end{array}$ & $500-3000 \mathrm{mg} /$ day & HIV Infections|AIDS & Phase 2 \\
\hline NCT01819701 & Antioxidant Enzymes Activities, Inflammation, and the Risk of CAD & $1000-2000 \mathrm{mg} /$ day & Coronary Artery Disease & Phase 2|Phase 3 \\
\hline NCT00091169 & Levocarnitine in Treating Fatigue in Cancer Patients & $500-1000 \mathrm{mg} /$ day & Fatigue & Phase 3 \\
\hline
\end{tabular}


Table 1. Cont

\begin{tabular}{|c|c|c|c|c|}
\hline NCT Number & Title & Dosage & Conditions & Phases \\
\hline & \multicolumn{4}{|l|}{ Combined Metabolic Cofactors } \\
\hline & & Serine: $20 \mathrm{~g} /$ day & & \\
\hline & & NAC: $5 \mathrm{~g} /$ day & & \\
\hline & Kinetics of Metabolic Cofactors (serine, NR, carnitine and NAC) in & Carnitine: $3 \mathrm{~g} /$ day & & \\
\hline \multirow[t]{5}{*}{ NCT03838822 } & NAFLD & NR: $1 \mathrm{~g} /$ day & Healthy & Phase 1 \\
\hline & & $\begin{array}{l}\text { Serine: } 12.35-24.7 \\
\text { g/dav }\end{array}$ & & \\
\hline & & NAC: $2.55-5.1 \mathrm{~g} /$ day & & \\
\hline & & Carnitine tartrate & & \\
\hline & & (\%73Carnitine): & & \\
\hline \multirow{6}{*}{ EudraCT_2018-000894-59 } & Supplementation of Metabolic Cofactors (serine, NR, carnitine and & $3.73-7.46$ g/day & & \\
\hline & NAC) in treatment of NAFLD & NR: 1-2 g/day & NAFLD & Phase 2 \\
\hline & & Serine: $12.35-24.7$ & & \\
\hline & & NAC: $2.55-5.1 \mathrm{~g} /$ day & & \\
\hline & & $\begin{array}{l}\text { Carnitine tartrate } \\
\text { (\%73Carnitine): }\end{array}$ & & \\
\hline & Supplementation of Metabolic Cofactors (serine, NR, carnitine and & $3.73-7.46 \mathrm{~g} /$ day & Parkinson Disease \& Alzheimer & \\
\hline NCTOXXXXX & NAC) in treatment of NAFLD & NR: 1-2 g/day & Disease & Phase 2 \\
\hline
\end{tabular}




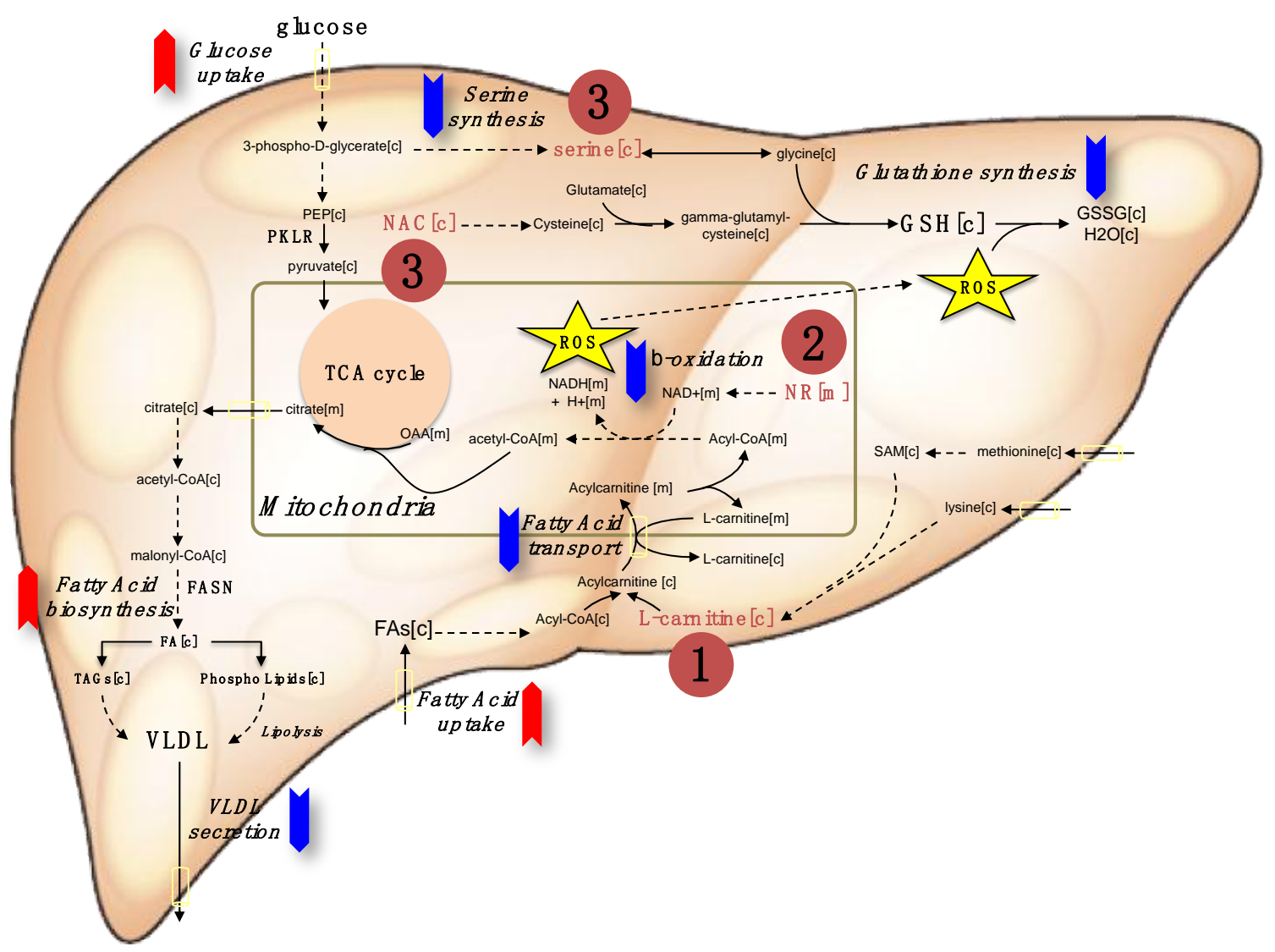

Figure 1. The red and blue arrows indicate the upregulation and down regulation of metabolic pathways in NAFLD, respectively. Metabolic cofactors can be supplemented to treat such metabolic abnormalities for effective treatment of the patients. The three-step strategy can be applied by supplementing (1) L-carnitine to enhance the transport of fatty acids across the mitochondrial membrane, (2) the NAD ${ }^{+}$ precursor nicotinamide riboside to enhance the $\beta$-oxidation of fatty acids in mitochondria, and the (3) glutathione (GSH) precursors including serine and N-acetyl-L-cysteine (NAC) to form GSH that is required to protect liver against free radical-mediated oxidative stress generated by the increased $\beta$-oxidation of fatty acids in the mitochondria. TCA: The citric acid cycle, VLDL: Very-low-density lipoprotein, ROS: Reactive oxygen species. PKLR: pyruvate kinase L/R, FASN: Fatty acid synthase.

\section{Potential Risks and Benefits of Metabolic Co-Factors}

Chronic metabolic disorders and aging are commonly associated with reduced plasma $\mathrm{NAD}^{+}$and GSH levels [22-24]. Since hepatocellular synthesis of GSH by de novo or by the salvation pathways are required; intracellular GSH levels cannot be increased by simply providing GSH supplements itself. Based on our integrative analysis, we found that the level of GSH is not enough to maintain and regulate the thiol redox status of the liver in subjects with high hepatic steatosis at fasting stage due to depletion of glycine and serine [25]. It has been shown that serine synthesis is downregulated in NAFLD patients [25] and supplementation of serine improved liver tissue function and decreased the liver steatosis in a proof of concept human study [21].

We aimed to decrease the level of liver fat content in NAFLD patients by increasing the hepatic levels of pivotal metabolic cofactors via simultaneous dietary supplementation of carnitine, NR, serine, and NAC. The study is based on a three-step strategy to increase the amount of fat oxidized in their liver (Figure 1). First, we included carnitine, which is transported by carnitine palmitoyltransferase (CPT) I and II and generates a long chain acetyl carnitine ester to facilitate the transport of fatty acids across the mitochondrial membrane. In addition to that, carnitine is important for exchanging acetyl groups and stabilization of acetyl-CoA and coenzyme A. Second, we included NR, a precursor of $\mathrm{NAD}^{+}$, to boost the level of hepatic mitochondrial $\beta$-oxidation of fatty acids and activate mitochondria. 
Decreased electron transport chain function combined with impaired rates of fatty acid $\beta$-oxidation leads to the accumulation of incomplete products of $\beta$-oxidation, which combined with increased levels of reactive oxygen species (ROS) contribute to insulin resistance. Finally, we included the two GSH precursors serine and NAC to increase GSH levels in the hepatocytes. Increased GSH levels may protect against free radical-mediated oxidative stress generated by the increased $\beta$-oxidation of fatty acids in mitochondria. Combined metabolic cofactors may concomitantly stimulate these three different metabolic pathways and activate the liver tissue metabolism in NAFLD patients.

Metabolic cofactors including carnitine, NR, serine, or NAC have been supplemented individually for treatment of different disorders (Table 1 and Table S1). Neither of them is known to have significant side effects or toxicity. Human clinical studies related to these metabolic cofactors as well as pharmacological data on each metabolic-cofactor is summarized below.

\subsection{L-Carnitine}

Carnitine is a white crystalline, hygroscopic powder and readily soluble in water and hot alcohol, and is insoluble in acetone. The absolute bioavailability of carnitine is $\sim 15-16 \%$. The mean distribution half-life is $\sim 0.6 \mathrm{~h}$ and the mean apparent terminal elimination half-life is $17.4 \mathrm{~h}$. Total body clearance of carnitine (Dose/AUC including endogenous baseline concentrations) is a mean of $4.00 \mathrm{~L} / \mathrm{h}$. Carnitine is not bound to plasma protein or albumin when tested at any concentration [26].

The major metabolites are trimethylamine $N$-oxide, excreted primarily in urine $(8 \%$ to $49 \%$ of the administered dose $)$ and $[3 \mathrm{H}]-\gamma$-butyrobetaine, excreted primarily in feces $(0.44 \%$ to $45 \%$ of the administered dose). Urinary excretion of carnitine is about 4 to $8 \%$ of the dose. Fecal excretion of total carnitine is less than $1 \%$ of the administered dose [27].

Carnitine is a naturally occurring substance required in mammalian energy metabolism. It is a carrier molecule that facilitates the transport of long-chain fatty acids across the inner mitochondrial membrane and delivers substrate for oxidation of fatty acids and subsequent energy production. Carnitine supplementation is recommended to the patients with inborn errors of metabolism and patients undergoing hemodialysis for kidney disease.

Carnitine deficiency is characterized with very low carnitine levels in plasma and tissues and may be either primary or secondary. Primary carnitine deficiency is an autosomal recessive disorder caused by a deficiency in the plasma membrane carnitine transporter and leads to urinary carnitine wasting [28]. SLC22A5 mutations can also affect carnitine transport and decrease plasma carnitine levels. In primary systemic deficiency, the clinical complications are associated with the recurrent episodes of Reye-like encephalopathy, hypoketotic hypoglycemia, and/or cardiomyopathy. Associated symptoms also include hypotonia, muscle weakness, and failure to thrive. In some patients, particularly those presenting with cardiomyopathy, carnitine supplementation may rapidly alleviate signs and symptoms. Secondary carnitine deficiency is associated with inadequate carnitine intake, decreased carnitine synthesis due to liver disorders, loss of carnitine during diarrhea, diuresis, or hemodialysis [29].

Carnitine is used in the treatment of primary and secondary carnitine deficiency [30]. It may also be recommended to the patients taking certain drugs (such as valproic acid for seizures or antibiotics for tuberculosis), or during medical procedures (hemodialysis for kidney disease) that deplete the body's carnitine deficiency [30].

Carnitine has also been supplemented to patients with heart failure, ischemic heart diseases, peripheral arterial diseases, HIV, male infertility, anorexia, chronic fatigue syndrome, and fatigue associated with chronic diseases and chronic obstructive pulmonary disease (Table 1). It is also used as a replacement supplement in strict vegetarians, dieters, and low-weight or premature infants. In athletes, carnitine has been used to improve performance, although the beneficial effects in athletes are not consisted in all studies. 


\subsubsection{Dosage}

The recommended daily dosage of carnitine is 1 to $3 \mathrm{~g}$, but higher doses have been used in clinical studies (see Table 1). Numerous studies have been performed:

$>$ In patients with carnitine depletion in peripheral blood mononuclear cells, carnitine has been supplemented at a dose of $6 \mathrm{~g} /$ day for 2 weeks [31].

$>$ Several studies have tested if carnitine supplementation promotes weight loss in obese subjects (4 $\mathrm{g} / \mathrm{L}, 8$ weeks) [32].

$>$ Efficacy and effectiveness of carnitine supplementation for cancer-related fatigue has been analyzed in a systematic literature review and meta-analysis. Nine studies used a dose between 2 to 6 g per day [33].

$>$ Impact of carnitine supplementation on plasma lipoprotein(a) concentrations have been analyzed in a recent systematic review and meta-analysis of human clinical trials. Studies used $2-4 \mathrm{~g} /$ day [34].

$>$ A systematic review was conducted to determine the effects of carnitine on all-cause mortality and cardiovascular morbidities in the setting of acute myocardial infarction (meta-analysis of five controlled trials, $n=3108$ ). There were no significant differences between the effects of daily carnitine supplementation of $2 \mathrm{~g}$ and $6 \mathrm{~g}$ on heart failure, unstable angina, or myocardial reinfarction [35].

$>$ The effect of carnitine supplementation on the regression of NASH was evaluated in 74 patients with a clinical and pathologic diagnosis of NASH [36]. The study subjects were randomly allocated to the placebo or to the carnitine ( $2 \mathrm{~g}$ per day divided into two equal doses for 24 weeks) groups. At the end of the study, carnitine-treated patients showed significant improvements in AST, ALT, gamma-GT, total cholesterol, LDL-cholesterol, HDL-cholesterols, triglycerides, glucose, HOMA-IR, C-reactive protein, TNF-alpha, and histological scores. Thus, carnitine supplementation reduced inflammation, and improved liver function, glucose plasma level, lipid profile, HOMA-IR, and histological manifestations of NASH.

\subsubsection{Safety Aspects}

Carnitine is usually well-tolerated and the FDA granted carnitine with Generally Recognized as Safe (GRAS) status. Various mild gastrointestinal complaints have been reported during the long-term administration of oral L- or D, carnitine; including transient nausea and vomiting, abdominal cramps, and diarrhea. At doses of approximately $3 \mathrm{~g} /$ day, carnitine supplements can cause nausea, vomiting, abdominal cramps, diarrhea, and a "fishy" body odor. Rare side effects include muscle weakness/mild myasthenia in uremic patients and seizures in those with seizure disorders.

Gastrointestinal adverse reactions with carnitine may be avoided by a slow consumption of the solution or by a greater dilution. Decreasing the dosage often diminishes or eliminates drug-related patient body odor or gastrointestinal symptoms when present. Tolerance should be monitored very closely during the first week of administration, and after any dosage increases.

It has been reported that the intestinal bacteria may metabolize carnitine to form a substance called Trimethylamine- $N$-oxide (TMAO) that might increase the risk of cardiovascular disease [37]. This effect appears to be more pronounced in people who consume meat than in vegans or vegetarians. The implications of these findings are not well understood and require more research.

There have been no reports of toxicity from carnitine over dosage. Carnitine is easily removed from plasma by dialysis. Large doses of carnitine may cause diarrhea. Pregnancy risk category of carnitine is B and it should be used during pregnancy only if it is clearly needed. Drug interaction with carnitine is very rare but it may decrease the effectiveness of the thyroid hormone and increase the effects of warfarin. 


\subsection{Nicotinamide Riboside}

NAD is an endogenous substance that is involved in several important cell functions such as signal transduction, DNA repair, and post-translational protein modifications. NAD-consuming activities and cell division necessitate ongoing NAD synthesis, either through a de novo pathway that originates with tryptophan or via salvage pathways from three $\mathrm{NAD}^{+}$precursor vitamins, NR, nicotinamide, and nicotinic acid. In animals, NAD generation is vital, since it is linked to several redox reactions in the body. NAD plays a central role in fatty acid metabolism, energy metabolism, and oxidative phosphorylation and is a key component of many metabolic pathways for carbohydrates, lipids, and amino acids.

NR is in wide use as an NAD+ precursor vitamin. It is available as an over-the-counter dietary supplement. The therapeutic potential of NAD has been investigated in several clinical conditions (e.g., aging), improving exercise performance, assisting weight loss and treating chronic fatigue syndrome [38]. Its effect has also been tested in improving depression, cognitive function, as well as treating patients with dyslipidemia, diabetes, Parkinson's disease, Alzheimer's disease, and dementia (Table 1).

\subsubsection{Dosage}

The daily dose of NR is 500-2000 mg in previously performed human clinical studies (Table 1). Numerous studies have been performed:

$>$ Trammell et al. determined the time and dose-dependent effects of NR on blood NAD ${ }^{+}$level in humans [39]. They reported that human blood level of $\mathrm{NAD}^{+}$can rise as much as 2.7-fold with a single oral dose of NR in a pilot study. They also demonstrated that single doses of 100, 300, and $1000 \mathrm{mg}$ of NR produce dose-dependent increases in the blood $\mathrm{NAD}^{+}$metabolome in the first clinical trial of NR pharmacokinetics in humans.

$>$ Airhart et al. recently reported an open-label, non-randomized study of the pharmacokinetics of $\mathrm{NR}$ and its effects on blood NAD ${ }^{+}$levels [40]. In eight healthy volunteers, $250 \mathrm{mg}$ NR was orally administered on days 1 and 2, then uptitrated to peak dose of $1000 \mathrm{mg}$ twice daily on days 7 and 8. On the morning of day 9, subjects completed a 24-hour pharmacokinetic study after receiving $1000 \mathrm{mg}$ NR at $t=0$. They analyzed whole-blood levels of NR, clinical blood chemistry, and $\mathrm{NAD}^{+}$levels and reported that oral NR was well tolerated with no adverse events. Significant increases comparing baseline to mean concentrations at steady state were observed for both NR $(p=0.03)$ and $\operatorname{NAD}^{+}(p=0.001)$; the latter increased by $100 \%$. Absolute changes from baseline to day 9 in NR and $\mathrm{NAD}^{+}$levels correlated highly $\left(R^{2}=0.72, p=0.008\right)$. The authors concluded that NR increases circulating $\mathrm{NAD}^{+}$in humans and it may be used in treatment of patients with diseases associated to mitochondrial dysfunction [40].

\subsubsection{Safety Aspects}

In 2016, the FDA granted NR with GRAS status on the basis of existing clinical study, which showed that the "no observed adverse effect level (NOAEL) was $300 \mathrm{mg} / \mathrm{kg} /$ day." NR seems safe for most people when used appropriately and short-term, up to 12 weeks [41]. It is also approved as a food ingredient in enhanced water products, protein shakes, nutrition bars, and chewing gum at no more than $0.027 \%$ by weight.

There was no mortality at an oral dose of $5000 \mathrm{mg} / \mathrm{kg}$. Based on the results of a 14-day study, a 90-day study was performed comparing NR at 300, 1000, and $3000 \mathrm{mg} / \mathrm{kg} /$ day to an equimolar dose of nicotinamide at $1260 \mathrm{mg} / \mathrm{kg} /$ day as a positive control. Results from the study show that NR had a similar toxicity profile to nicotinamide at the highest dose tested. The lowest observed adverse effect level for NR was $1000 \mathrm{mg} / \mathrm{kg} /$ day, and the no observed adverse effect level was $300 \mathrm{mg} / \mathrm{kg} /$ day.

Flushing is the most sensitive side effect of nicotinic acid supplementation. After ingestion of supplemental nicotinamide, no cases of flushing or glucose intolerance have been reported and only 
one case of hepatitis was reported following the ingestion of greater than $3 \mathrm{~g} /$ day for several days. Such side-effects have not been reported for supplementation of NR. NR was not genotoxic but data on its use during pregnancy and breast-feeding is inadequate. There is no known drug interaction with the supplementation of NR.

\subsection{L-Serine}

Serine is a non-essential amino acid; however, under certain circumstances, vertebrates cannot synthesize it in sufficient quantities to meet necessary cellular demands. Serine is biosynthesized in the mammalian system from 3-phosphoglycerate and serves as a precursor for the synthesis of the amino acids including glycine and cysteine. Physiologically, it has a variety of roles, perhaps most importantly as a phosphorylation site in proteins. Mutations in the metabolic enzymes that synthesize serine have been implicated in various human diseases.

\section{Dosage}

The FDA determined serine with GRAS status and it appears to be neuroprotective. The daily dose of serine is 1-30 $\mathrm{g}$ in previous human clinical studies (Table 1), but higher doses have been used in some clinical studies (Table 1). Numerous studies have been performed including:

> Serine supplementation (three daily doses of $5 \mathrm{~g}$ of serine [i.e., $190 \mathrm{mg} / \mathrm{kg}$ ]) has also been shown to be safe even in pregnancy, as shown by in pre- and postnatal treatment of 3-phosphoglycerate-dehydrogenase deficiency [42,43].

$>$ Hereditary sensory and autonomic neuropathy type 1 (HSAN1) is a disorder caused by missense mutations in the enzyme serine palmitoyltransferase (SPT) [44]. Subjects received daily supplements of powdered serine (mixed in water) on a low- or high-dose schedule (200 or $400 \mathrm{mg} / \mathrm{kg}$ body weight, respectively; $n=7$ per group). Results showed that an altered substrate selectivity of the mutant SPT is key to the pathophysiology of HSAN1 and raise the prospect of serine supplementation as a first treatment option for this disorder [44].

$>\quad$ In our previous study, we assessed the effect of dietary supplementation with serine $(200 \mathrm{mg} / \mathrm{kg}$ per day) for 2 weeks on fatty liver and fasting levels of plasma markers of liver functions in six obese subjects with NAFLD. Our analysis showed that supplementation of serine improved markers of liver tissue function and significantly decreased liver fat [21].

$>$ Fridman et al. performed a randomized, double-blind, placebo-controlled trial $(n=18)$ to evaluate the efficacy and safety of serine treatment for adults with hereditary sensory and autonomic neuropathy type 1 (HSAN1). The study subjects were randomized to serine $(400 \mathrm{mg} / \mathrm{kg} / \mathrm{day})$ or placebo for one year. All participants received serine during the second year. Analysis of vital signs, physical examination findings, and clinical laboratory examinations did not reveal adverse effects of serine. Thus, long-term serine supplementation did not reveal adverse effects of serine [45].

\subsection{N-Acetyl-L-Cysteine}

NAC is a white to white with light yellow cast powder, and has a pKa of 9.5 at $30^{\circ} \mathrm{C}$. NAC is stable in gastric and intestinal fluids and rapidly absorbed after oral administration. It is not affected by food intake. It reaches peak plasma concentration in 30-60 min after application. The distribution volume $(\mathrm{Vd})$ is between 0.33 and $0.47 \mathrm{~L} / \mathrm{kg}$, which is evident in extracellular fluids and passes primarily to the lung, kidney and liver. After oral administration, $48 \%$ of the amount passed to the blood is determined in the lungs. The rate of binding to plasma proteins is about $50 \%$. NAC is extensively metabolized in liver, and $22-30 \%$ is excreted in urine in the form of sulfate and taurine. NAC has a half-life of $5.6-6 \mathrm{~h}$ in adults. 
NAC is the $\mathrm{N}$-acetyl derivative of the amino acid L-cysteine and it is an essential precursor in the formation of the antioxidant glutathione within the human body. Hence, administration of NAC replenishes glutathione stores.

Glutathione may act as an endogenous neuromodulator, modulate the redox state of the $\mathrm{N}$-methyl-D-aspartate receptor complex, and activate ionotropic receptors that are different from any other excitatory amino acid receptor, which may constitute glutathione receptors, potentially making it a neurotransmitter [46]. Since NAC is a prodrug of glutathione, it may modulate some/all of the glutathione receptors. It has potential to confer antioxidant effects and may reduce free radicals. NAC also possesses some anti-inflammatory effects possibly via inhibiting NF- $\mathrm{kB}$ and modulating cytokine synthesis [47].

NAC has two approved indications: (i) treatment of paracetamol (acetaminophen) overdose associated with liver damage and (ii) removal of thick mucus in individuals with cystic fibrosis or chronic obstructive pulmonary disease. NAC has also been tested for contrast induced nephropathy, infertility, cystic fibrosis, ischemic heart diseases, HIV, hypercholesterolemia, and schizophrenia (Table S1). It is beneficial effect has been reported in any kind of acute hepatic failure and treatment of liver diseases as discussed below.

\subsubsection{Dosage}

The daily dose of NAC is $1-5 \mathrm{~g}$ in previous human clinical studies (Table S1), but higher doses have been used in different clinical studies (Table S1).

NAC is available as intravenous (IV) and oral formulations. The IV injection and inhalation preparations are, in general, prescription only, whereas the oral solution and the effervescent tablets are available over the counter in many countries including the United States. Daily dose of NAC is $200 \mathrm{mg}$ capsules taken 3 times a day (morning, lunch, evening) or a single dose of $600 \mathrm{mg}$ (3 capsules) in the evening. In paracetamol poisoning, the loading dose is $\sim 140 \mathrm{mg} / \mathrm{kg}$, and the maintenance dose is $70 \mathrm{mg} / \mathrm{kg}$ every $4 \mathrm{~h}$ (17 doses). Numerous studies have been performed:

$>$ In early psychosis, NAC was administered at a dose of $2700 \mathrm{mg} /$ day for 6 months in a double-blind placebo-controlled trial [48].

$>$ NAC was administered to enhance performance of elite sport. A recent systematic review of the literature evaluated the effect of NAC supplementation. The typical daily dose of NAC reported was $5.8 \mathrm{~g} /$ day; with a range between 1.2 and $20.0 \mathrm{~g} /$ day [49].

$>$ The effect of NAC supplementation on oxidative stress status and alveolar inflammation was analyzed in a double-blind, randomized clinical trial using a dose of $1800 \mathrm{mg} /$ day for 4 months in people exposed to asbestos [50].

$>$ NAC was administered in oral doses of 6000-8000 mg daily for several months in HIV-infected patients. It had a good safety profile and minimal adverse effects [51].

$>$ NAFLD patients $(n=30)$ were randomly selected to receive either NAC (600 mg per $12 \mathrm{~h})$ or vitamin C (1000 mg per $12 \mathrm{~h}$ ) [52]. Liver function tests (ALT, AST and ALP) were measured as well as the grade of steatosis, the pattern of its echogenicity, the span of the liver and the spleen, and the portal vein diameter before the intervention. Patients were followed up using the same method of evaluation repeated in the first, second, and third months. NAC resulted in a significant decrease of serum ALT after three months, compared to vitamin C. This effect was independent of the grade of steatosis in the initial diagnosis. It has been reported that NAC significantly decrease the span of the spleen and it can be used to improve liver function in patients with NAFLD [52].

$>$ The therapeutic effect of NAC in the treatment of NASH was investigated in 35 patients diagnosed with NASH based on liver biopsy. Patients were divided into two groups: the first (18 patients) was administered NAC $600 \mathrm{mg} /$ day orally for 4 weeks, while the control group (17 patients) was followed up without therapy. Results did not show improved liver function in this study. It has 
been reported that the daily amount of glutathione synthesis in humans is 10-15 $\mathrm{g}$ and most of the sources of this are provided from the natural sources of the organism. Therefore, the authors hypothesized that the lower dosage of NAC (600 mg/day) might not affect glutathione synthesis to a great extent [53].

$>$ To test whether glutathione deficiency occurs due to the diminishd synthesis and contributes to oxidative stress, eight elderly (60-75 years) and eight younger (30-40 years) subjects received stable-isotope infusions of $\left[{ }^{2} \mathrm{H}(2)\right]$ glycine, after which red blood cell (RBC) glutathione synthesis and concentrations, plasma oxidative stress, and markers of oxidant damage were measured. Results showed that glutathione deficiency in elderly humans occurs because of a marked reduction in synthesis, and that dietary supplementation with the two glutathione precursors cysteine (as NAC) and glycine fully restores glutathione synthesis and concentrations and lowers levels of oxidative stress and oxidant damages [54].

\subsubsection{Safety Aspects}

Side effects occur rarely with NAC usage. Even at very high doses, serious adverse events or signs of intoxication have not been observed. Most common adverse reactions (incidence greater than $2 \%$ ) are rash, urticaria/facial flushing, pruritus, nausea, and vomiting. Adverse effects for oral formulations of NAC have been reported to include nausea, vomiting, rash, and fever.

Although unclear, there was a trend of increasing side effects with increasing doses and IV usage of NAC compared with placebo. Anaphylactic reactions, i.e., pruritus, rash, angioedema, bronchospasm, tachycardia, and hypotension have been previously reported to occur within $30 \mathrm{~min}$ after IV loading dose of NAC in $\sim 3-6 \%$ of people. Hypersensitivity reactions, including generalized urticaria, have been observed in patients receiving oral NAC for acetaminophen overdose, but anaphylaxis has rarely been reported with oral administration.

Occasionally, severe and persistent vomiting occurs as a symptom of acute acetaminophen overdose. Treatment with NAC may aggravate the vomiting and increase the risk of upper gastrointestinal hemorrhage in at risk patients (e.g., those with esophageal varices, peptic ulcers, etc.).

Large doses in a mouse model showed that NAC could potentially cause damage to the heart and lungs. It has been shown that NAC was metabolized to $S$-nitroso- $N$-acetylcysteine, which increased blood pressure in the lungs and right ventricle of the heart (pulmonary artery hypertension) in mice treated with NAC. The effect was similar to that observed following a three-week exposure to an oxygen-deprived environment (chronic hypoxia). The authors also found that $S$-nitroso- $N$-acetylcysteine induced a hypoxia-like response in the expression of several important genes both in vitro and in vivo.

No specific antidote is currently available; supportive and symptomatic treatments are performed. NAC is contraindicated in patients with previous allergic/anaphylactoid reaction to NAC. Patients with acute asthma attacks can also not use NAC. Pregnancy risk category of NAC is B. There is insufficient data on the usage in pregnancy and lactation and it should only be used if it is necessary. Drug interaction with NAC is very rare. Minor interactions have been reported with parenteral nitroglycerine and oral forms of nitrates. NAC has no effect on the use of vehicles and machinery.

\section{Conclusions}

Here, we reviewed the dosage and known safety of carnitine, NR, serine, and NAC in different human clinical trials with a special emphasis on human safety. Three of the compounds are found naturally as constituents in food, except for NAC, which is a drug, despite its primary metabolite being cysteine. These metabolic cofactors can be tested in future and clinical implications in single or combined form for treatment of different diseases.

The concept that substrate deficiencies for metabolic enzymes underlie the progression of and may even be the causes of human diseases, and it has rarely been mechanistically explored for different diseases. Based on our integrative systems level analysis, we suggested the use of carnitine, NR, 
serine, and NAC for effective treatment of NAFLD. Of note, following the failure of recent clinical trials targeting single molecule or pathway; current NASH studies show that the trend towards targeting multiple pathways employing combination therapeutics. This is in line with changing our understanding of NASH pathogenesis from double-hit to multiple-hit hypothesis [55]. Therefore, a combination of supplements targeting several NASH pathways would probably be more appropriate.

From a toxicological point of view, using nutritional substances rarely causes safety issues in humans. The "safe doses" for most nutritional/food substances are already known in humans and, unlike most pharmaceuticals, there is often a very large margin to toxicity using nutritional compounds. As an example, the dose at which vitamin $B_{12}$ becomes toxic for humans is over 100-fold higher than the recommended daily intake. The reason for this low toxicity of nutritional substances is because they are generally directly or indirectly metabolized via cellular metabolic pathways. The products are easily dealt with either by shuffling substrate-overload to other metabolic pathways, or used as building blocks of other compounds (such as glycogen, fat, proteins), or excreted from the cell or body.

Despite this, many calls to national poison centers occur every year due to ingestion of high doses of vitamins and minerals, especially for the fat-soluble vitamins A, D, and iron. Regarding pharmaceuticals, with the exception of some antibiotics, very few drugs are given in gram (g) doses. Most drugs are metabolized in the liver in order to aid excretion from the body. Almost all medical drugs are foreign to the body, and their individual structures and use are largely directed to alteration of an enzyme or receptor activity, before being excreted from the body. Hence, during the supplementation of these metabolic cofactors in human clinical trials, patients should be screened carefully to avoid potential side effects on liver, heart and kidney functions.

We demonstrated that simultaneous supplementation of combined metabolic cofactors may improve the efficacy of the intervention in patients with NAFLD and decreases liver fat [21]. Considering that NAFLD, obesity, type 2 diabetes, neurodegenerative diseases, and cardiovascular diseases are common conditions that regularly co-exist and act synergistically [56]. Furthermore, it has a similar pathogenesis with alcoholic fatty liver disease [57]; such metabolic cofactors can also be used in the treatment of the subjects with such disorders after testing its effect in placebo-controlled human clinical studies.

Supplementary Materials: The following are available online at http://www.mdpi.com/2072-6643/11/7/1578/s1, Table S1: The dosages of the Nicotinamide Riboside, L-serine, L-carnitine and N-acetyl-L-cysteine used in previous human trials. The data retrieved from https://clinicaltrials.gov.

Funding: This research was funded by Knut and Alice Wallenberg Foundation, grant number 2017.0303 and The APC was also funded by Knut and Alice Wallenberg Foundation.

Acknowledgments: The authors would like to thank reviewers for providing constructive comments and Jens Nielsen for editorial comments.

Conflicts of Interest: The authors declare no conflict of interest.

\section{References}

1. Francque, S.M.; Van Der Graaff, D.; Kwanten, W.J. Non-alcoholic fatty liver disease and cardiovascular risk: Pathophysiological mechanisms and implications. J. Hepatol. 2016, 65, 425-443. [CrossRef] [PubMed]

2. Samuel, V.T.; Shulman, G.I. Nonalcoholic fatty liver disease as a nexus of metabolic and hepatic diseases. Cell Metab. 2018, 27, 22-41. [CrossRef] [PubMed]

3. Solinas, G.; Borén, J.; Dulloo, A.G. De novo lipogenesis in metabolic homeostasis: More friend than foe? Mol. Metab. 2015, 4, 367-377. [CrossRef] [PubMed]

4. Lonardo, A.; Ballestri, S.; Marchesini, G.; Angulo, P.; Loria, P. Nonalcoholic fatty liver disease: A precursor of the metabolic syndrome. Dig. Liver Dis. 2015, 47, 181-190. [CrossRef] [PubMed]

5. Younossi, Z.M.; Koenig, A.B.; Abdelatif, D.; Fazel, Y.; Henry, L.; Wymer, M. Global epidemiology of nonalcoholic fatty liver disease-Meta-analytic assessment of prevalence, incidence, and outcomes. Hepatology 2016, 64, 73-84. [CrossRef] 
6. Rinella, M.; Charlton, M. The globalization of non-alcoholic fatty liver disease-Prevalence and impact on world health. Hepatology 2016, 64, 19-22. [CrossRef] [PubMed]

7. Younossi, Z.M.; Blissett, D.; Blissett, R.; Henry, L.; Stepanova, M.; Younossi, Y.; Racila, A.; Hunt, S.; Beckerman, R. The economic and clinical burden of nonalcoholic fatty liver disease in the United States and Europe. Hepatology 2016, 64, 1577-1586. [CrossRef]

8. Dyson, J.K.; Anstee, Q.M.; McPherson, S. Non-alcoholic fatty liver disease: A practical approach to treatment. Front. Gastroenterol. 2014, 5, 277-286. [CrossRef]

9. Anstee, Q.M.; Targher, G.; Day, C.P. Progression of NAFLD to diabetes mellitus, cardiovascular disease or cirrhosis. Nat. Rev. Gastroenterol. Hepatol. 2013, 10, 330-344. [CrossRef]

10. Liu, Z.; Que, S.; Mardinoglu, A. Rediscussion on linearity between fibrosis stages and mortality risk in nonalcoholic fatty liver disease patients. Hepatology 2017, 66, 1357-1358. [CrossRef]

11. Tilg, H.; Moschen, A.R.; Roden, M. NAFLD and diabetes mellitus. Nat. Rev. Gastroenterol. Hepatol. 2017, 14, 32-42. [CrossRef] [PubMed]

12. Ballestri, S.; Nascimbeni, F.; Romagnoli, D.; Baldelli, E.; Targher, G.; Lonardo, A. Type 2 diabetes in non-alcoholic fatty liver disease and hepatitis c virus infection-Liver: The "Musketeer" in the spotlight. Int. J. Mol. Sci. 2016, 17, 355. [CrossRef] [PubMed]

13. Lovric, A.; Granér, M.; Bjornson, E.; Arif, M.; Benfeitas, R.; Nyman, K.; Ståhlman, M.; Pentikäinen, M.O.; Lundbom, J.; Hakkarainen, A.; et al. Characterization of different fat depots in NAFLD using inflammation-associated proteome, lipidome and metabolome. Sci. Rep. 2018, 8, 14200. [CrossRef] [PubMed]

14. Lee, S.; Zhang, C.; Liu, Z.; Klevstig, M.; Mukhopadhyay, B.; Bergentall, M.; Cinar, R.; Ståhlman, M.; Sikanic, N.; Park, J.K.; et al. Network analyses identify liver-specific targets for treating liver diseases. Mol. Syst. Biol. 2017, 13, 938. [CrossRef] [PubMed]

15. Mardinoglu, A.; Borén, J.; Smith, U.; Uhlén, M.; Nielsen, J. Systems biology in hepatology: Approaches and applications. Nat. Rev. Gastroenterol. Hepatol. 2018, 15, 365-377. [CrossRef] [PubMed]

16. Mardinoglu, A.; Uhlen, M.; Borén, J. Broad views of non-alcoholic fatty liver disease. Cell Syst. 2018, 6, 7-9. [CrossRef] [PubMed]

17. Bosley, J.; Boren, C.; Lee, S.; Grøtli, M.; Nielsen, J.; Uhlen, M.; Boren, J.; Mardinoglu, A. Improving the economics of NASH/NAFLD treatment through the use of systems biology. Drug Discov. Today 2017, 22, 1532-1538. [CrossRef] [PubMed]

18. Adiels, M.; Mardinoglu, A.; Taskinen, M.-R.; Borén, J. Kinetic studies to elucidate impaired metabolism of triglyceride-rich lipoproteins in humans. Front. Physiol. 2015, 6, 586. [CrossRef]

19. Mardinoglu, A.; Heiker, J.T.; Gärtner, D.; Björnson, E.; Schön, M.R.; Flehmig, G.; Klöting, N.; Krohn, K.; Fasshauer, M.; Stumvoll, M.; et al. Extensive weight loss reveals distinct gene expression changes in human subcutaneous and visceral adipose tissue. Sci. Rep. 2015, 5, 14841. [CrossRef]

20. Mardinoglu, A.; Wu, H.; Björnson, E.; Zhang, C.; Hakkarainen, A.; Räsänen, S.M.; Lee, S.; Mancina, R.M.; Bergentall, M.; Pietiläinen, K.H.; et al. An integrated understanding of the rapid metabolic benefits of a carbohydrate-restricted diet on hepatic steatosis in humans. Cell Metab. 2018, 27, 559-571. [CrossRef]

21. Mardinoglu, A.; Bjornson, E.; Zhang, C.; Klevstig, M.; Söderlund, S.; Ståhlman, M.; Hallström, B.M. Personal model-assisted identification of NAD+ and glutathione metabolism as intervention target in NAFLD. Mol. Syst. Biol. 2017, 13, 916. [CrossRef] [PubMed]

22. Yang, Y.; Sauve, A.A. NAD(+) metabolism: Bioenergetics, signaling and manipulation for therapy. Biochim. Biophys. Acta 2016, 1864, 1787-1800. [CrossRef] [PubMed]

23. Massudi, H.; Grant, R.; Braidy, N.; Guest, J.; Farnsworth, B.; Guillemin, G.J. Age-associated changes in oxidative stress and NAD+ metabolism in human tissue. PLoS ONE 2012, 7, e42357. [CrossRef] [PubMed]

24. Ballatori, N.; Krance, S.M.; Notenboom, S.; Shi, S.; Tieu, K.; Hammond, C.L. Glutathione dysregulation and the etiology and progression of human diseases. Biol. Chem. 2009, 390, 191-214. [CrossRef]

25. Mardinoglu, A.; Ågren, R.; Kampf, C.; Asplund, A.; Uhlen, M.; Nielsen, J. Genome-scale metabolic modelling of hepatocytes reveals serine deficiency in patients with non-alcoholic fatty liver disease. Nat. Commun. 2014, 5, 3083. [CrossRef]

26. Marzo, A.; Martelli, E.A.; Mancinelli, A.; Cardace, G.; Corbelletta, C.; Bassani, E.; Solbiati, M. Protein binding of L-carnitine family components. Eur. J. Drug Metab. Pharmacokinet. 1991, 3, 364-368. 
27. Rebouche, C.J. Quantitative estimation of absorption and degradation of a carnitine supplement by human adults. Metabolism 1991, 40, 1305-1310. [CrossRef]

28. Magoulas, P.L.; El-Hattab, A.W. Systemic primary carnitine deficiency: An overview of clinical manifestations, diagnosis, and management. Orphanet J. Rare Dis. 2012, 7, 68. [CrossRef]

29. Bonafe, L.; Berger, M.M.; Que, Y.A.; Mechanick, J.I. Carnitine deficiency in chronic critical illness. Curr. Opin. Clin. Nutr. Metab. Care 2014, 17, 200-209. [CrossRef]

30. Angelini, C. Systemic Primary Carnitine Deficiency. In Genetic Neuromuscular Disorders; Springer: Cham, Switzerland, 2018.

31. De Simone, C.; Famularo, G.; Tzantzoglou, S.; Trinchieri, V.; Moretti, S.; Sorice, F. Carnitine depletion in peripheral blood mononuclear cells from patients with AIDS: effect of oral L-carnitine. AIDS 1994, 8, 655-660. [CrossRef]

32. Villani, R.G.; Gannon, J.; Self, M.; Rich, P.A. L-carnitine supplementation combined with aerobic training does not promote weight loss in moderately obese women. Int. J. Sport Nutr. Exerc. Metab. 2000, 10, $199-207$. [CrossRef] [PubMed]

33. Marx, W.; Teleni, L.; Opie, R.; Kelly, J.; Marshall, S.; Itsiopoulos, C.; Isenring, E. Efficacy and effectiveness of carnitine supplementation for cancer-related fatigue: A systematic literature review and meta-analysis. Nutrients 2017, 9, 1224. [CrossRef] [PubMed]

34. Serban, M.C.; Mikhailidis, D.P.; Toth, P.; Jones, S.; Muntner, P.; Blaha, M.; Andrica, F.; Martin, S.; Lip, G.Y.; Ray, K.K.; et al. Impact of L-carnitine on plasma lipoprotein(a) concentrations: A systematic review and meta-analysis of randomized controlled trials. J. Am. Coll. Cardiol. 2016, 67, 2032. [CrossRef]

35. Shang, R.; Sun, Z.; Li, H. Effective dosing of L-carnitine in the secondary prevention of cardiovascular disease: A systematic review and meta-analysis. BMC Cardiovasc. Disord. 2014, 14, 88. [CrossRef]

36. Malaguarnera, M.; Gargante, M.P.; Russo, C.; Antic, T.; Vacante, M.; Malaguarnera, M.; Avitabile, T.; Volti, G.L.; Galvano, F. L-Carnitine supplementation to diet: A new tool in treatment of nonalcoholic steatohepatitis-A randomized and controlled clinical trial. Am. J. Gastroenterol. 2010, 105, 1338-1345. [CrossRef] [PubMed]

37. Koeth, R.A.; Lam-Galvez, B.R.; Kirsop, J.; Wang, Z.; Levison, B.S.; Gu, X.; Culley, M.K. L-carnitine in omnivorous diets induces an atherogenic gut microbial pathway in humans. J. Clin. Invest. 2019, 129, 373-387. [CrossRef] [PubMed]

38. Pankiewicz, K.; Chen, L.; Petrelli, R.; Felczak, K.; Gao, G.; Bonnac, L.; Yu, J.; Bennett, E. Nicotinamide adenine dinucleotide based therapeutics. Curr. Med. Chem. 2008, 15, 650-670. [CrossRef]

39. Trammell, S.A.J.; Schmidt, M.S.; Weidemann, B.J.; Redpath, P.; Jaksch, F.; Dellinger, R.W.; Li, Z.; Abel, E.D.; Migaud, M.E.; Brenner, C. Nicotinamide riboside is uniquely and orally bioavailable in mice and humans. Nat. Commun. 2016, 7, 12948. [CrossRef]

40. Airhart, S.E.; Shireman, L.M.; Risler, L.J.; Anderson, G.D.; Gowda, G.N.; Raftery, D.; O’Brien, K.D. An open-label, non-randomized study of the pharmacokinetics of the nutritional supplement nicotinamide riboside (NR) and its effects on blood NAD+ levels in healthy volunteers. PLoS ONE 2017, 12, e0186459. [CrossRef]

41. Martens, C.R.; Denman, B.A.; Mazzo, M.R.; Armstrong, M.L.; Reisdorph, N.; McQueen, M.B.; Seals, D.R. Chronic nicotinamide riboside supplementation is well-tolerated and elevates $\mathrm{NAD}(+)$ in healthy middle-aged and older adults. Nat. Commun. 2018, 9, 1286. [CrossRef]

42. De Koning, T.J. Treatment with amino acids in serine deficiency disorders. J. Inherit. Metab. Dis. 2006, 29, 347-351. [CrossRef] [PubMed]

43. De Koning, T.J.; Klomp, L.W.J.; Van Oppen, A.C.C.; Beemer, F.A.; Dorland, L.; Van Den Berg, I.E.T.; Berger, R. Prenatal and early postnatal treatment in 3-phosphoglycerate-dehydrogenase deficiency. Lancet 2004, 364, 2221-2222. [CrossRef]

44. Garofalo, K.; Penno, A.; Schmidt, B.P.; Lee, H.-J.; Frosch, M.P.; Von Eckardstein, A.; Brown, R.H.; Hornemann, T.; Eichler, F.S. Oral l-serine supplementation reduces production of neurotoxic deoxysphingolipids in mice and humans with hereditary sensory autonomic neuropathy type 1. J. Clin. Investig. 2011, 121, 4735-4745. [CrossRef] [PubMed]

45. Fridman, V.; Suriyanarayanan, S.; Novak, P.; David, W.; Macklin, E.A.; McKenna-Yasek, D.; Walsh, K.; Aziz-Bose, R.; Oaklander, A.L.; Brown, B.; et al. Randomized trial of 1-serine in patients with hereditary sensory and autonomic neuropathy type 1. Neurology 2019, 92, e359-e370. [CrossRef] [PubMed] 
46. Oja, S. Modulation of glutamate receptor functions by glutathione. Neurochem. Int. 2000, 37, $299-306$. [CrossRef]

47. Berk, M.; Malhi, G.S.; Gray, L.J.; Dean, O.M. The promise of N-acetylcysteine in neuropsychiatry. Trends Pharmacol. Sci. 2013, 34, 167-177. [CrossRef] [PubMed]

48. Conus, P.; Seidman, L.J.; Fournier, M.; Xin, L.; Cleusix, M.; Baumann, P.S.; Golay, P. N-acetylcysteine in a double-blind randomized placebo-controlled trial: Toward biomarker-guided treatment in early psychosis. Schizophr. Bull. 2018, 44, 317-327. [CrossRef]

49. Rhodes, K.; Braakhuis, A. Performance and side effects of supplementation with N-acetylcysteine: A systematic review and meta-analysis. Sports Med. 2017, 47, 1619-1636. [CrossRef]

50. Alfonso, H.; Franklin, P.; Ching, S.; Croft, K.; Burcham, P.; Olsen, N.; Reid, A.; Joyce, D.; De Klerk, N.; Musk, A.B. Effect of $\mathrm{N}$-acetylcysteine supplementation on oxidative stress status and alveolar inflammation in people exposed to asbestos: A double-blind, randomized clinical trial. Respirology 2015, 20, 1102-1107. [CrossRef]

51. De Rosa, S.; Zaretsky, M.; Dubs, J.; Roederer, M.; Anderson, M.; Green, A.; Mitra, D.; Watanabe, N.; Nakamura, H.; Tjioe, I.; et al. N-acetylcysteine replenishes glutathione in HIV infection. Eur. J. Clin. Investig. 2000, 30, 915-929. [CrossRef]

52. Khoshbaten, M.; Aliasgarzadeh, A.; Masnadi, K.; Tarzamani, M.K.; Farhang, S.; Babaei, H.; Kiani, J.; Zaare, M.; Najafipoor, F. N-acetylcysteine improves liver function in patients with non-alcoholic fatty liver disease. Zahedan J. Res. Med. Sci. 2010, 10, 12-16.

53. Pamuk, G.E.; Sonsuz, A. N-acetylcysteine in the treatment of non-alcoholic steatohepatitis. J. Gastroenterol. Hepatol. 2003, 18, 1220-1221. [CrossRef] [PubMed]

54. Sekhar, R.V.; Patel, S.G.; Guthikonda, A.P.; Reid, M.; Balasubramanyam, A.E.; Taffet, G.; Jahoor, F. Deficient synthesis of glutathione underlies oxidative stress in aging and can be corrected by dietary cysteine and glycine supplementation1234. Am. J. Clin. Nutr. 2011, 94, 847-853. [CrossRef] [PubMed]

55. Buzzetti, E.; Pinzani, M.; Tsochatzis, E.A. The multiple-hit pathogenesis of non-alcoholic fatty liver disease (NAFLD). Metabolism 2016, 65, 1038-1048. [CrossRef] [PubMed]

56. Hazlehurst, J.M.; Woods, C.; Marjot, T.; Cobbold, J.F.; Tomlinson, J.W. Non-alcoholic fatty liver disease and diabetes. Metabolism 2016, 65, 1096-1108. [CrossRef] [PubMed]

57. Lakshman, R.; Shah, R.; Reyes-Gordillo, K.; Varatharajalu, R. Synergy between NAFLD and AFLD and potential biomarkers. Clin. Res. Hepatol. Gastroenterol. 2015, 39, S29-S34. [CrossRef] [PubMed] 